\title{
An Analysis of Maxillary Anterior Teeth Crown Width-Height Ratios: A Photographic, Three-Dimensional, and Standardized Plaster Model's Study
}

\author{
Naseer Ahmed $\mathbb{D}^{1,2}$ Mohamad Syahrizal Halim ${ }^{10},{ }^{3}$ Ayesha Aslam, ${ }^{4}$ Zuryati Ab Ghani $\mathbb{D}^{5}$ \\ Jawad Safdar $\left(\mathbb{D},{ }^{6}\right.$ and Mohammad Khursheed Alam (iD) ${ }^{7,8,9}$ \\ ${ }^{1}$ Prosthodontics Unit, School of Dental Sciences, Health Campus, Universiti Sains Malaysia, Kubang Kerian, 16150 Kota Bharu, \\ Kelantan, Malaysia \\ ${ }^{2}$ Department of Prosthodontics, Altamash Institute of Dental Medicine, Karachi 75500, Pakistan \\ ${ }^{3}$ Conservative Dentistry Unit, School of Dental Sciences, Health Campus, Universiti Sains Malaysia, Kubang Kerian, \\ 16150 Kota Bharu, Kelantan, Malaysia \\ ${ }^{4}$ Department of Prosthodontics, Army Medical College/Armed Forces Institute of Dentistry, National University of Medical Sciences, \\ Islamabad, Pakistan \\ ${ }^{5}$ Prosthodontics Unit, School of Dental Sciences, Health Campus, Universiti Sains, Kubang Kerian, 16150 Kota Bharu, \\ Kelantan, Malaysia \\ ${ }^{6}$ Department of Oral and Maxillofacial Surgery. Dow Dental College, Dow University of Health Sciences, Karachi, Pakistan \\ ${ }^{7}$ Department of Preventive Dentistry, College of Dentistry, Jouf University, Sakaka, Al Jouf 72345, Saudi Arabia \\ ${ }^{8}$ Centre for Transdisciplinary Research (CFTR), Saveetha Dental College, Saveetha Institute of Medical and Technical Sciences, \\ Saveetha University, Chennai 600077, India \\ ${ }^{9}$ Department of Public Health, Faculty of Allied Health Sciences, Daffodil International University, Dhaka 1207, Bangladesh
}

Correspondence should be addressed to Mohamad Syahrizal Halim; drsyah@usm.my

and Mohammad Khursheed Alam; mkalam@ju.edu.sa

Received 13 October 2021; Accepted 25 January 2022; Published 7 February 2022

Academic Editor: Iole Vozza

Copyright ( 92022 Naseer Ahmed et al. This is an open access article distributed under the Creative Commons Attribution License, which permits unrestricted use, distribution, and reproduction in any medium, provided the original work is properly cited.

Objective. To analyze the width and height ratios of maxillary anterior teeth at different crown levels through photographs, $3 \mathrm{D}$, and plaster dental model techniques in a subset of the Pakistani population. Material and Methods. This clinical study consisted of 230 participants. The maxillary impression, standardized photographs, and models were constructed for crown width and height analysis. The SPSS version 25 was used for statistical analysis. Descriptive statistics were carried out for mean, standard deviation, and percentage calculation of teeth width and height, gender, and age of participants. Paired $t$-test analysis was carried out to compare the dependent variables (teeth size, width, and height ratios) with independent variables (techniques applied, side disparity). A $p$ value of $\leq 0.05$ was considered statistically significant. Results. The mean width and height of maxillary anterior teeth obtained through photographs, 3D, and plater models were statistically different. The 3D dental model analysis showed reliable and accurate results. The mean width and height ratio of teeth were different on both sides of the arch. There was a significant difference $(p=0.001)$ in crown width-height ratios at different crown levels. Conclusion. The width and height ratios in the studied population were different at various crown levels. The dimensions of teeth varied from the incisal to the cervical part of the crown. Hence, rather than relying on a single, fixed ratio of $78 \%$ to $80 \%$ suggested by researchers for anterior teeth, the clinician should adopt different crown width-height ratios to restore teeth with the optimum esthetic outcome. 


\section{Introduction}

Esthetic restoration of smiles is a complicated process mandating a multidisciplinary approach [1]. The major concern for patients seeking esthetic dental treatment is the appearance of anterior teeth [2]. Among other parameters, the dimensions of maxillary anterior teeth are the most significant factors in achieving harmonious and esthetic outcomes [3]. However, defining ideal tooth dimensions is rather difficult owing to individual variations and proximal tooth wear [4].

Maxillary anterior teeth, being the most prominent ones, are paramount to the restoration of anterior dental esthetics as well as overall facial esthetics [5]. Selection of appropriate crown length and width is essential to creating esthetically pleasing smiles. Crown width to length ratio is considered as the most stable parameter, essential to achieve a harmony between dental esthetics and facial contours [6]. For maxillary anterior teeth, several theories exist suggesting the ideal proportions that may result in esthetic results such as golden proportion, golden percentage, and recurring esthetic dental proportion [7].

The ratio between height and width of maxillary anterior has been assessed using several methods. Sterret et al. [8] employed dental casts to assess the crown width to height ratio (CWHR) of maxillary anterior teeth. They reported a CWHR of $85 \%, 76 \%$, and $77 \%$ for males and $86 \%, 79 \%$, and $81 \%$ for females for maxillary central incisors, lateral incisors, and canines, respectively. Magne et al., in contrast, utilized extracted teeth to measure CWHR and observed mean ratios of 78\% for central incisors and 73\% each for lateral incisors and canines [9]. While Chu [10] reported a CWHR of 78\% for all maxillary anterior teeth using "Chu's esthetic proportion gauge," Shahid et al. [11] and Yuan et al. [5] utilized digital calipers to measure the dimensions of maxillary teeth and reported significant differences only in terms of crown widths and height between males and females and not in CWHR. With advancements in digital dentistry, 3D digital models and software are now being used for easier and faster measurements of dental clinical parameters [7, 12].

As previously stated, knowledge about crown width and height $(W / H)$ ratio is critical for optimal restoration of maxillary anterior teeth. A study presenting crown width-height ratio of maxillary anterior teeth at different crown levels is lacking. The present study, therefore, is aimed at determining the crown width-height ratio of maxillary anterior teeth at different clinical crown levels utilizing 2D photographs, plaster, and 3D digital dental models. Specific objectives of the study included the following:

(i) To evaluate the mean mesiodistal widths and incisocervical lengths of maxillary anterior teeth using 2D photographs, 3D models, and standard plaster models

(ii) To evaluate the mesiodistal widths and incisocervical lengths of maxillary anterior teeth using 2D photographs, 3D models, and standard plaster models at different crown levels (iii) To evaluate the width-height ratios of maxillary anterior teeth at different crown levels

(iv) To compare the mean width-height ratios of maxillary anterior teeth at different crown levels

\section{Materials and Methods}

2.1. Study Setting and Sample Size. This analytical study was carried out at the Altamash Institute of Dental Medicine, Pakistan. A total of 230 subjects participated in this study. The age range of participants was 18 to 30 years. A nonprobability convenience sampling technique was used to recruit participants in this study. The flow diagram of the stepwise methodological approach adopted in this study is described in Figure 1. The sample size was calculated with public service of creative research systems survey software (creative research systems, version 9, Petaluma, California, United States). Considering the width and height ratio of $85.55 \%$ for central incisor [13], the estimated sample size at 5\% margin of error with 95\% confidence interval, 230 individuals with intact natural maxillary anterior teeth were invited to participate in this study, considering the $10,000,000$ population.

\subsection{Participant Recruitment and Ethical Consideration. The} ethical permission was obtained from the ethical review board of AIDM number AIDM/EC/06/2019/06 and Universiti Sains Malaysia number USM/JEPeM/19060380. The participants were interviewed. The informed consent for voluntary participation and refusal at any time from the study was carried out for each participant. The form number, nationality, age, gender, height, weight of participants, and contact details were noted. The intraoral and extraoral examination was carried out to eliminate facial malformation, asymmetry, deviation of temporomandibular joint, and difficulty in mouth opening. The participants were also screened for dental caries, any restoration in anterior teeth, malalignment of teeth, gingival inflammation, and history of orthodontic treatment. Two hundred and fifty participants were initially screened to be included in the study. Later, 20 participants were excluded based on malalignment of teeth, facial asymmetry, restored teeth, i.e., composite restoration, crown, and bridgework, subjects with blur/unclear photographs, impression making errors, and broken or destroyed dental casts in the process of fabrication.

2.3. Capturing Retracted Smile Intraoral Photograph. A digital camera (Canon EOS, DSLR Camera, CMOS, 18 MP,1920 $\mathrm{X} 1080 \mathrm{p} / 30 \mathrm{fps}$ ) was used to capture crisp clear images. The camera was equipped with a built-in magnification lens of $(18-55 \mathrm{~mm}+75-300 \mathrm{~mm})$ to capture reproducible images. The 1:1 macro setting was used for close-up photography of teeth and generally included 4 four maxillary incisors and canine teeth on the sensor. The $1: 1$ setting was used for capturing anterior teeth images with a focus set on subject's central incisor tooth. The camera was set at the 12 o'clock position, mounted on a tripod with a standardized focus and distance of 1.5 meters from the participants to ensure distortion-free images. The surrounding lighting remained 


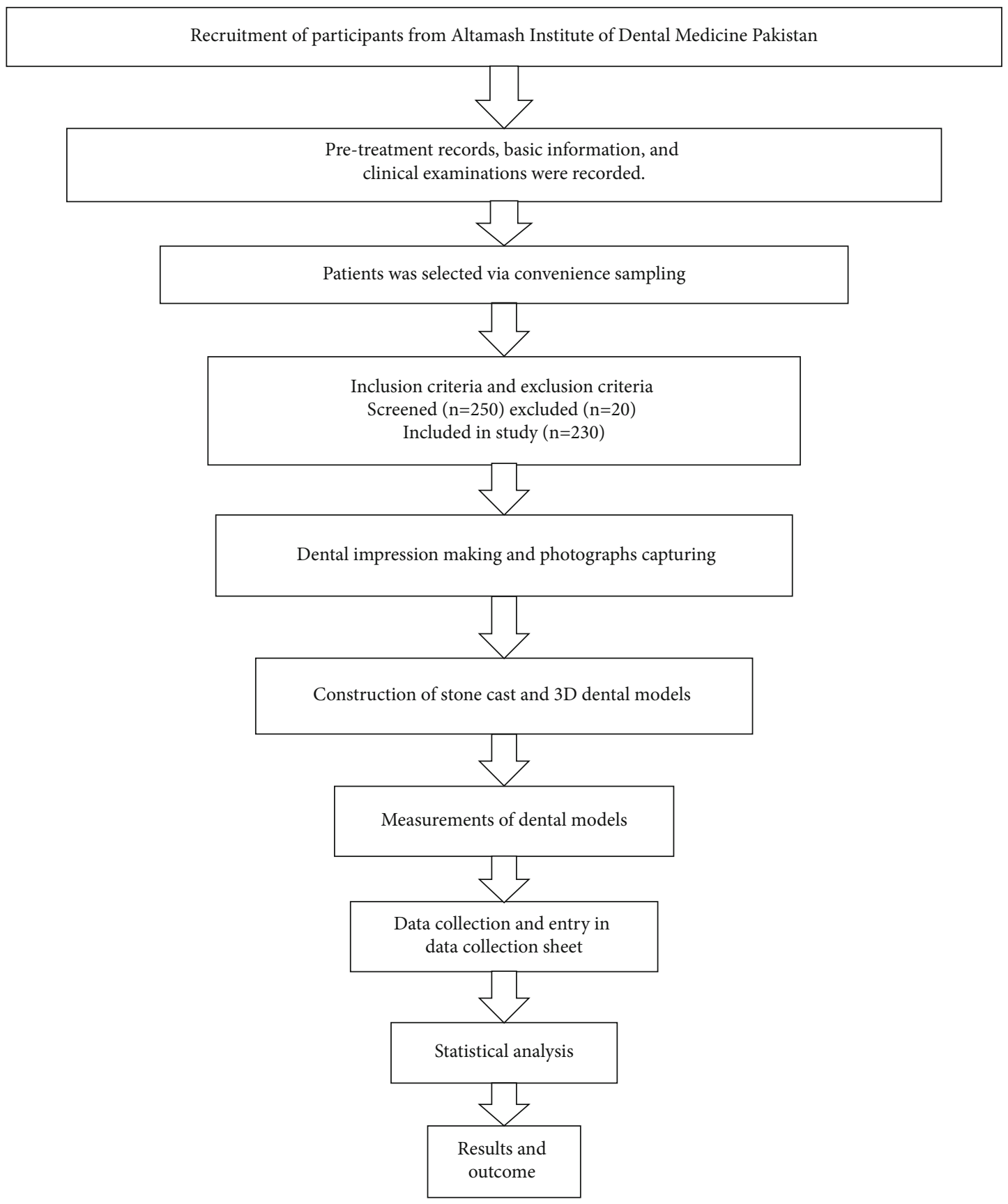

Figure 1: Flow diagram of the study methodology.

the same for all the photographs. A ring flashlight source system (LED-FD,480II, Medike Photo and Video Co., Ltd. Yidoblo, Guangdong, China) was used, and its configuration consisted of a light unit that was mounted next to the camera lens. The design was of a movable type which consisted of a light (fluorescent) that was mounted further from the lens placed in variable custom positions around a circular mounting bracket. A photograph of anterior teeth for assessment of study subjects was taken from the front, with the subject in a seated position. The head position was guided by the investigator to assist the participants in assuming their natural head position. The height of the lens of the camera was adjusted on the tripod to match the level of the incisors for retracted smile image capture. The participants were seated upright with shoulders and head held straight and facing forward, looking straight ahead at the lens of the camera; the natural head position was standardized along both horizontal and vertical axes. In all intraoral photos, the upper and lower lips were retracted to display the maxillary anterior teeth. This procedure was like the protocol described by Bidra et al. [14] (Figure 2).

2.4. Maxillary Impression and Dental Cast Making. For the fabrication of the maxillary cast, the perforated type of stainless-steel maxillary impression tray was carefully selected; the tray must cover the hamular notches and fovea 


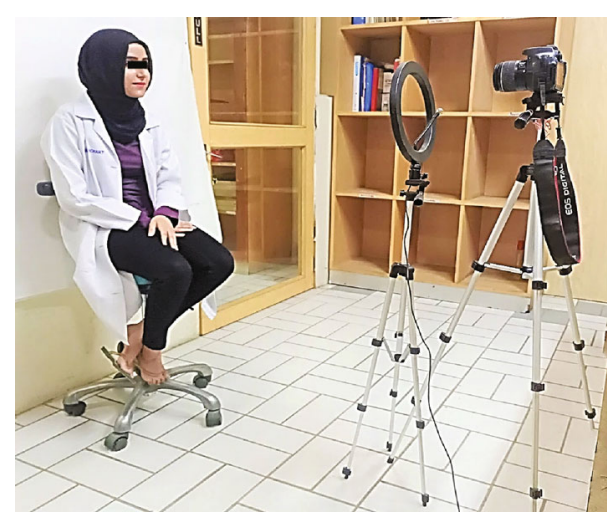

Figure 2: Pictorial illustration showing methodology of obtaining standard digital images with subject in natural head position.

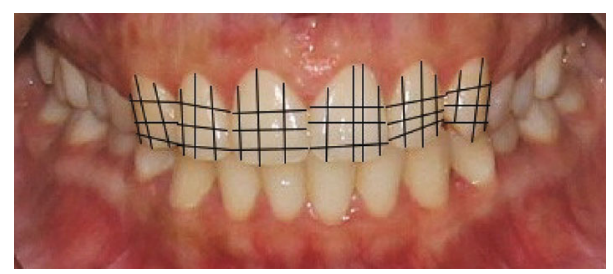

FIGURE 3: Demonstrating the method applied to measure maxillary anterior teeth width and height.

palatine and also provide adequate space for 3-4 millimeters for the impression material uniformly. The borders of the tray were extended up to the functional sulcus depth without causing physical discomfort to the participants.

The impressions of the maxillary arch were made of all subjects using irreversible hydrocolloid material (fast setting alginate hydrogum; Zharmack Spa). It was manipulated according to manufacturer's instructions. The errorless impressions after making were washed under running tap water for 10 seconds to remove debris and salivary pellicle. Every impression was immersed in dimethyl ammonium chloride solution (BODE) for 10 minutes to achieve disinfection. After disinfection, a serial number was allotted to each impression for identification purposes. The impressions were poured with type IV dental stone (ISO Type 3, Elite Rock Zharmack Spa). The dental cast was removed from the impression after 30 minutes to avoid errors like dimensional changes and desiccation of the cast by the set impression material. After removal, the cast was coded with a serial number of subjects using a permanent marker. The bases of casts were made with soft plaster using standardized base formers. To obtain a 3D model, the cast was scanned by UP3D Dental Laboratory Scanner (UP360+, $300 \times 300 \times$ $400 \mathrm{~mm}, 3 \mathrm{D}$ scanner, Shenzhen, China). The scanner was equipped with 2.0 MP cameras that can scan with high precision up to $6 \mu \mathrm{m}$. The full-arch 3D scan was obtained in 20 seconds. The scanned images were displayed on a compatible dental design software (UPCAD, UP3D, Shenzhen, China), then transferred via USB to store in a personal computer.
2.5. Plaster, Photographic, and 3D Dental Cast Teeth Width Measurement. The photographic and 3D dental cast mesiodistal width of the maxillary anterior teeth was recorded with a measuring tool in millimeters setting through Photoshop software (Adobe, version 21.0.2, San Jose, California, United States). The plaster dental cast widths were calculated with a sharp-tipped digital Vernier calliper (Neiko 01407A Electronic Digital Calliper), read to the nearest $0.02 \mathrm{~mm}$. The mesiodistal widths of central incisors, lateral incisors, and canines were measured from the facial side.

The width of the maxillary anterior teeth crown was measured at the incisal third, middle third, and cervical third of the crown from the labial aspect. The height of the crown was measured from 3 aspects; the mesial third of the crown from incisal edge to base of interdental papilla similarly at the distal third the crown length was measured in millimeters and recorded. The crown height was also measured at the middle one-third from the incisal edge to the deepest point in the cervical third of the crown (Figure 3). The information regarding teeth measurements obtained from all three sources was recorded and transferred to a computer spreadsheet.

2.6. Calculation of Crown Width and Height Ratios. To calculate the crown width and height $(W / H)$ ratios, the incisal third width was divided by mesial third height, middle third width was divided by middle third crown height, and cervical third width was divided by distal third crown height. This way, the width and height ratio of each tooth was calculated at three different crown levels.

2.7. Validity and Reliability Assessment. The data methods and collection were performed by a single operator (N.A.). Initially, for interoperator assessment, the data collection was performed by a senior colleague (J.S.). The data was then subjected to correlation analysis; a strong correlation value of (0.739) was noted between the operator measurements.

To minimize intraoperator errors, each measurement was performed thrice; a constant or mean value of variables was then noted in proforma. Furthermore, $20 \%$ of photographs and dental models were assessed after 2 weeks by the same operator. The data was analyzed later by the Dahlberg formula to detect intraoperator reliability through correlation statistics.

For validity purposes, $20 \%$ of dental cast measurements that were carried out with a Vernier calliper were compared with 3D dental cast measurements through adobe photoshop software (Adobe, version 21.0.2, San Jose, California, United States). The intraclass correlation coefficient test (ICC) was carried to obtain an association between the two sets of measurements. A strong correlation value of (0.816) was found because of the analysis.

To minimize the photographic error, the actual width of maxillary anterior teeth obtained from the dental cast was divided by perceived width from photographs to obtain a conversion factor [15]. The perceived teeth widths were then multiplied by the conversion factor, to overcome magnification error and achieve the true width captured in the photograph. 
TABLE 1: Distribution of mean maxillary anterior teeth widths obtained from 2D images and 3D and plaster dental models $(n=230)$.

\begin{tabular}{lcccccc}
\hline \multirow{2}{*}{ Maxillary teeth } & \multicolumn{2}{c}{ 2D photographic width } & \multicolumn{2}{c}{ 3D digital model width } & \multicolumn{2}{c}{ Plaster dental cast width } \\
& Mean & Standard deviation & Mean & Standard deviation & Mean & Standard deviation \\
\hline Right central incisor & 16.114 & 2.366 & 8.397 & 0.540 & 8.627 & 0.453 \\
Right lateral incisor & 13.888 & 5.156 & 7.735 & 0.554 & 7.371 & 0.539 \\
Right canine & 11.079 & 3.093 & 8.042 & 0.390 & 7.864 & 0.457 \\
Left central incisor & 16.366 & 5.655 & 8.788 & 0.426 & 0.723 & 7.623 \\
Left lateral incisor & 13.308 & 1.318 & 7.847 & 0.620 & 7.959 & 0.479 \\
Left canine & 10.937 & 0.803 & 8.157 & 0.464 & 48.170 & 1.551 \\
Combine six teeth width & 81.722 & 9.924 & 48.969 & 1.508 & 482 \\
\hline
\end{tabular}

2D: two-dimensional; 3D: three-dimensional.

TABLE 2: Comparison of mean maxillary anterior teeth widths obtained from $2 \mathrm{D}$ images and clean width obtained after photographic error assessment $(n=230)$.

\begin{tabular}{|c|c|c|c|c|}
\hline \multirow{2}{*}{ Maxillary teeth } & \multicolumn{2}{|c|}{$\begin{array}{l}\text { 2D photographic } \\
\text { width }\end{array}$} & \multicolumn{2}{|c|}{ Clean width } \\
\hline & Mean & $\begin{array}{l}\text { Standard } \\
\text { deviation }\end{array}$ & Mean & $\begin{array}{l}\text { Standard } \\
\text { deviation }\end{array}$ \\
\hline $\begin{array}{l}\text { Right central } \\
\text { incisor }\end{array}$ & 16.114 & 2.366 & 8.130 & 0.717 \\
\hline $\begin{array}{l}\text { Right lateral } \\
\text { incisor }\end{array}$ & 13.888 & 5.156 & 6.241 & 0.903 \\
\hline Right canine & 11.079 & 3.093 & 6.619 & 1.319 \\
\hline $\begin{array}{l}\text { Left central } \\
\text { incisor }\end{array}$ & 16.366 & 5.655 & 7.965 & 0.848 \\
\hline Left lateral incisor & 13.308 & 1.318 & 5.983 & 0.937 \\
\hline Left canine & 10.937 & 0.803 & 6.384 & 1.320 \\
\hline $\begin{array}{l}\text { Combine six teeth } \\
\text { width }\end{array}$ & 81.722 & 9.924 & 40.788 & 4.090 \\
\hline
\end{tabular}

Clean width: mesiodistal teeth dimension obtained after photographic error estimation assessment; 2D: two-dimensional $(p<0.05)$.

TABLE 3: Comparison of different combined mesiodistal widths of six maxillary anterior teeth $(n=230)$.

\begin{tabular}{lcc}
\hline Variables & Mean & Standard deviation \\
\hline 2D photographic & 81.722 & 9.924 \\
3D digital model & 48.969 & 1.508 \\
Clean mesiodistal teeth width & 40.788 & 4.090 \\
Plaster dental cast & 48.170 & 1.551 \\
\hline
\end{tabular}

2.8. Statistical Analysis. The data were analyzed with Statistical Package for the Social Sciences Software (IBM, SPSS Statistics, version 25, Chicago, Illinois, United States). The distribution of data was analysed with normality plots and testing (Shapiro-Wilk and Kolmogorov-Smirnov). Descriptive analysis of categorical (gender) and continuous (age, teeth width, height, and ratios) variables was performed, to calculate frequency, percentage, mean, and standard deviation. Moreover, mean values of dependent variables (width and height ratios of maxillary anterior teeth) were compared using paired $t$-test to detect the mean differences and side disparity. A $p$ value $\leq 0.05$ was taken as statistically significant.

\section{Results}

The dropout rate of participants in this study was $0.08 \%$. The mean age of the participants was $24.210 \pm 3.541$. There were $112(48.7 \%)$ male and 118 (51.3\%) female participants in this study.

The mean width of maxillary anterior teeth obtained through 2D dental images was recorded $16.114 \pm 2.366$ for right central incisor, $13.888 \pm 5.156$ for right lateral incisors, and $11.079 \pm 3.093$ for a canine tooth. The mean width of the left central incisor was $16.366 \pm 5.655,13.308 \pm 1318$ lateral incisor, and $10.937 \pm 0.803$ for a canine tooth.

The mean width of maxillary anterior teeth obtained through $3 \mathrm{D}$ dental images was $8.397 \pm 0.540$ in the right central incisor, $7.735 \pm 0.554$ right lateral incisor, and $8.042 \pm 0.390$ for a canine tooth. The mean width of the left central incisor was $8.788 \pm 0.426,7.847 \pm 0.620$ lateral incisors, and $8.157 \pm 0.464$ in the canine tooth.

The mean width of maxillary anterior teeth obtained through plaster dental cast was $8.627 \pm 0.453$ in the right central incisor, $7.371 \pm 0.539$ in the right lateral incisor, and $7.864 \pm 0.457$ for a canine tooth. The mean width of the left central incisor was $8.723 \pm 0.479$, while $7.623 \pm$ 0.637 in the lateral incisor and $7.959 \pm 0.482$ in the canine tooth (Table 1).

The clean width of maxillary anterior teeth in this study was $8.130 \pm 0717$ in the right central incisor, while for the lateral incisor, it was $6.241 \pm 0.903$, and $6.619 \pm 1.319$ in the canine tooth, whereas in left central incisor $7.965 \pm$ 0.848 , lateral incisor $5.983 \pm 0.937$, and $6.384 \pm 1.320$ in the canine tooth. There was a significant difference $(p<0.05)$ between the mean values of photographic and clean widths of maxillary anterior teeth (Table 2).

The combined width of maxillary anterior teeth analyzed through $2 \mathrm{D}$ photographs were $81.722 \pm 9.924$, 3D digital models were $48.969 \pm 1.508$, clean mesiodistal width was $40.788 \pm 4.090$, and plaster dental cast was $48.170 \pm 1.551$ (Table 3).

The mean mesiodistal widths of the right central incisor at incisal one-third of the crown was $8.912 \pm 0.476$, middle third $8.623 \pm 0.444$, and cervical third $8.354 \pm 0.487$. The lateral incisor incisal one-third width was $7.826 \pm 0.602$, the middle third width was $8.623 \pm 0.444$, and the width at cervical third was $8.354 \pm 0.487$. Canine tooth incisal onethird width was $8.364 \pm 0.457$, middle one-third width was 
TABLE 4: Characteristics of mesiodistal widths of maxillary anterior teeth different crown level $(n=230)$.

\begin{tabular}{lccc}
\hline Variables & $\begin{array}{c}\text { Incisal third } \\
\text { width }\end{array}$ & $\begin{array}{c}\text { Middle third } \\
\text { width }\end{array}$ & $\begin{array}{c}\text { Cervical third } \\
\text { width }\end{array}$ \\
\hline $\begin{array}{l}\text { Right central } \\
\text { incisor }\end{array}$ & $8.912 \pm 0.476$ & $8.623 \pm 0.444$ & $8.354 \pm 0.487$ \\
$\begin{array}{l}\text { Right lateral } \\
\text { incisor }\end{array}$ & $7.826 \pm 0.602$ & $7.371 \pm 0.539$ & $6.366 \pm 0.543$ \\
$\begin{array}{l}\text { Right canine } \\
\text { Left central } \\
\text { incisor }\end{array}$ & $8.364 \pm 0.457$ & $7.864 \pm 0.457$ & $6.864 \pm 0.457$ \\
$\begin{array}{l}\text { Left lateral } \\
\text { incisor }\end{array}$ & $8.123 \pm 0.637$ & $7.623 \pm 0.637$ & $6.623 \pm 0.637$ \\
Left canine & $8.455 \pm 0.475$ & $7.959 \pm 0.482$ & $6.984 \pm 0.489$ \\
\hline
\end{tabular}

TABLE 5: Characteristics of incisocervical length of maxillary anterior teeth at different crown levels $(n=230)$.

\begin{tabular}{lccc}
\hline Variables & $\begin{array}{c}\text { Mesial third } \\
\text { length }\end{array}$ & $\begin{array}{c}\text { Middle third } \\
\text { length }\end{array}$ & $\begin{array}{c}\text { Distal third } \\
\text { length }\end{array}$ \\
\hline $\begin{array}{l}\text { Right central } \\
\text { incisor }\end{array}$ & $8.023 \pm 0.908$ & $9.990 \pm 0.883$ & $7.059 \pm 0.921$ \\
$\begin{array}{l}\text { Right lateral } \\
\text { incisor }\end{array}$ & $7.611 \pm 0.603$ & $9.093 \pm 0.642$ & $6.608 \pm 0.613$ \\
$\begin{array}{l}\text { Right canine } \\
\begin{array}{l}\text { Left central } \\
\text { incisor }\end{array}\end{array}$ & $7.305 \pm 0.638$ & $8.805 \pm 0.638$ & $7.235 \pm 0.635$ \\
$\begin{array}{l}\text { Left lateral } \\
\text { incisor }\end{array}$ & $7.196 \pm 0.670$ & $8.485 \pm 0.691$ & $7.456 \pm 0.713$ \\
Left canine & $7.281 \pm 0.665$ & $8.839 \pm 0.884$ & $6.766 \pm 0.775$ \\
\hline
\end{tabular}

$7.864 \pm 0.457$, while the mean cervical third width was $6.864 \pm 0.457$.

Similarly, on the left side of the arch, the mean incisal one-third width of the central incisor tooth was $9.219 \pm$ 0.506 , middle third width recorded $8.723 \pm 0.479$, and cervical third $7.765 \pm 0.526$; as far as the lateral incisor is concerned, the mean incisal one-third width was $8.123 \pm 0.637$ , middle one-third $7.623 \pm 0.637$, and cervical one-third was $6.623 \pm 0.637$. Whereas the mean width of the canine tooth at incisal one-third was $8.455 \pm 0.475$, the middle third was $7.959 \pm 0.482$, and at the cervical one-third, it was $6.984 \pm 0.489$ (Table 4).

Furthermore, the mean length of maxillary anterior teeth at different crown levels was the following. The mesial onethird length of the right central incisor was $8.023 \pm 0.908$, the middle third length was $9.990 \pm 0.883$, and the distal third length was $7.059 \pm 0.921$, whereas in lateral incisor, mesial third length was $7.611 \pm 0.603$, middle third length was $9.093 \pm 0.642$, while the distal third length was recorded as $6.608 \pm 0.613$. The mesial third length of the canine tooth was $7.305 \pm 0.638$, the middle third length was $8.805 \pm 0.638$ , and the cervical third was $7.235 \pm 0.635$.

However, on the left side of the arch, the mean mesial one-third length of the central incisor tooth was $7.435 \pm$
0.558 , middle third length $8.929 \pm 0.520$, and the distal third was $7.059 \pm 0.623$. As far as the lateral incisor is concerned, the mean mesial one-third length was $7.196 \pm 0.670$, middle one-third length $8.485 \pm 0.691$, and distal one-third was $7.456 \pm 0.713$, whereas the mean length of the canine tooth at mesial one-third was $7.281 \pm 0.665$, middle third 8.839 \pm 0.884 , and at the distal one-third, it was $6.766 \pm 0.775$ (Table 5).

The $W / H$ ratios of maxillary anterior teeth at different crown levels revealed a value of $112.245 \pm 13.443$ at incisal one-third in the right central incisor, while 87.271 \pm 8.798 at the middle third of the crown, and $120.286 \pm 16.753$ at a cervical third of the crown. Similarly, the width to height ratio at incisal one-third of the right lateral incisor was $99.738 \pm 13.479$, the middle one-third ratio was $98.965 \pm$ 14.596, whereas at the cervical third, the ratio obtained was $97.143 \pm 13.315$. The incisal one-third width and height ratio of the right canine was $113.773 \pm 17.642$, the middle third ratio was $88.651 \pm 12.509$, and the cervical third was $95.682 \pm 14.268$.

Moreover, the width to height ratio of maxillary anterior teeth at the left side of the arch revealed a ratio of 124.178 \pm 10.436 at incisal one-third in the left central incisor, $98.202 \pm 6.781$ at the middle third of the crown, while $110.570 \pm 9.846$ for the cervical third of the crown. Additionally, the width to height ratio at incisal one-third of left lateral incisor was $113.226 \pm 15.983$, the middle one-third ratio was $89.830 \pm 11.437$, whereas at the cervical third, the ratio of $89.527 \pm 12.697$ was found. The incisal one-third width and height ratio of the left canine was $114.978 \pm$ 17.024 , the middle third was $96.446 \pm 111.824$, and the cervical third was $102.848 \pm 15.729$ (Table 6).

Table 7 is presenting paired $t$-test analysis of crown $W / H$ ratios at different crown levels. There was a significant difference $(p=0.001)$ between width and height ratio of central incisor at incisal third, supported by a greater $t$-value of -11.932 indicating a large difference between the mean values. The width-height ratio at the middle third was also significant $(p=0.001)$, shown by a large $t$-value $(-16.034)$. Similarly, the cervical third width and height ratios were also statistically significant $(p=0.001)$, and a large $t$-value was noted (7.895).

Furthermore, the comparison of side disparity in maxillary anterior teeth revealed a significant difference $(p=0.001$ ) between the width and height ratio of lateral incisor at incisal third, aided by a greater $t$-value of (12.033) indicating a large difference between the mean values. The width-height ratio at the middle third showed a significant difference $(p=0.001)$, supported by a large $t$-value (9.568). Likewise, the cervical third width and height ratio was also statistically significant $(p=0.001)$, endorsed by a large $t$-value (8.092).

However, no significant difference $(p=0.296)$ was found between the width and height ratio of the canine tooth at incisal third level, supported by a small $t$-value of -1.048 indicating no variation between the mean values. The width-height ratio at the middle third was also statistically significant $(p=0.001)$; this finding was supported by a $t$ -value (-3.404). Likewise, the cervical third level width and height ratios showed a significant difference $(p=0.001)$ in mean values, indicated by a large $t$-value $(-17.145)$. 
TABLE 6: Distribution of width-height ratios of maxillary anterior teeth at different crown levels $(n=230)$.

\begin{tabular}{lccc}
\hline Variables & $\begin{array}{c}\text { Incisal third width and height ratio } \\
\% \text { SD }\end{array}$ & $\begin{array}{c}\text { Middle third width and height ratio } \\
\% \text { SD }\end{array}$ & $\begin{array}{c}\text { Cervical third width and height ratio } \\
\% \text { SD }\end{array}$ \\
\hline Right central incisor & $112.245 \pm 13.443$ & $87.271 \pm 8.798$ & $120.286 \pm 16.753$ \\
Right lateral incisor & $99.738 \pm 13.479$ & $98.965 \pm 14.596$ & $97.143 \pm 13.315$ \\
Right canine & $113.773 \pm 17.642$ & $88.651 \pm 12.509$ & $95.682 \pm 14.268$ \\
Left central incisor & $124.178 \pm 10.436$ & $98.202 \pm 6.781$ & $110.570 \pm 9.846$ \\
Left lateral incisor & $113.226 \pm 15.983$ & $89.830 \pm 11.437$ & $89.527 \pm 12.697$ \\
Left canine & $114.978 \pm 17.024$ & $96.446 \pm 111.824$ & $102.848 \pm 15.729$ \\
\hline
\end{tabular}

$\%$ : percentage; SD: standard deviation.

\section{Discussion}

The present study is aimed at evaluating the crown widthheight ratio of maxillary anterior teeth at different clinical crown levels utilizing 2D photographs and 3D digital dental models. The mean combined mesiodistal widths of maxillary anterior teeth were $81.722 \pm 9.924$ for 2D photographs, $48.969 \pm 1.508$ using 3D digital models, $40.788 \pm 4.090$ clean width after error correction for 2D photographs, and 48.170 \pm 1.551 using plaster models. A statistically significant difference $(p<0.05)$ between the mean values of photographic and clean widths of maxillary anterior teeth was seen. The values of photographic width were drastically different form clean width of anterior teeth; the reason is lack of minimizing the photographic error during capture. The images get distorted and enlarged due to difference in a camera focal length, shutter speed, and macro settings; hence, it effects a photograph accuracy and reproducibility. The current study overcomes the distortion effect by adopting the "conversion factor" method proposed by Ward [15] to obtain an accurate and reproducible dental images. The use of such photographic error assessment techniques was also recommended in other studies carried out by Kois [16] and Pitel et al. [17].

In this study, a statistically significant difference $(p=0.001$ ) was observed between the width and height ratio of all right and left side anterior teeth at incisal, middle, and cervical thirds except for maxillary canine where the width-height ratio at incisal third was not statistically significant $(p=0.296)$. The crown width and height ratios were measured at different anatomical levels in this study; therefore, a single value of $\mathrm{W} / \mathrm{H}$ ratio (73 to 95\%) like proposed by Shahid et al. [11] in both sexes that was concluded, based on the middle third width and height of the teeth, and further compared with arch form, arch perimetry and width cannot be compared with our study due to difference in methodology.

In the present study, for maxillary anterior teeth, the greatest crown dimensions were observed for maxillary central incisors, followed by maxillary canines and maxillary lateral incisors. This is by the findings of Alqahtani et al. [2], Sitthiphan et al. [6], Sah et al. [18], Orozco-Varo et al. [19], and Aldegheishem et al. [20]. In the current study, the mean width-height ratio for the right central incisor at the incisal, middle, and cervical thirds of the crown was $112.24 \%$, $87.27 \%$, and $120.286 \%$, respectively (mean: $106.59 \%$ ), while for the left central incisor, these ratios were $124.17 \%, 98.2 \%$, and $110.57 \%$, respectively (mean: $110.98 \%$ ). Likewise, for the right lateral incisor, mean width-height ratios were $99.7 \%$, 98.9\%, and 97.1\% (mean: 98.56\%), and for the left lateral incisor, mean width-height ratios were $113.22 \%, 89.8 \%$, and 89.52\% (mean: $97.5 \%$ ). For the right canine, mean widthheight ratios were $113.77 \%, 88.65 \%$, and $95.68 \%$ (mean: $99.36 \%$ ), while for the left canine, ratios were $114.97 \%$, $96.44 \%$, and $102.84 \%$ (mean: $104.75 \%$ ). Song et al. [21] in their study carried out similar work but measured the crown widthheight ratios at two levels only, namely, mesiodistal width to length $(\mathrm{MDW} / \mathrm{L})$ ratio and the cervical width to length $(\mathrm{CW} / \mathrm{L})$ ratio. They reported a mean $\mathrm{MDW} / \mathrm{L}$ of $86 \%$ and $\mathrm{CW} / \mathrm{L}$ of $73 \%$ for the central incisors, $84 \% \mathrm{MDW} / \mathrm{L}$ and $67 \%$ $\mathrm{CW} / \mathrm{L}$ for lateral incisors, and $87 \% \mathrm{MDW} / \mathrm{L}$ and $71 \% \mathrm{CW} / \mathrm{L}$ ratio for maxillary canines in the Korean population indicating an increased length of teeth in the said population. These differences can be attributed to differences in ethnicity that have been suggested to affect tooth dimensions among populations [22].

In the present study, the mean width and height of central incisors were $8.59 \mathrm{~mm}$ and $8.08 \mathrm{~mm}$, respectively. For lateral incisors, the mean width and length were $7.32 \mathrm{~mm}$ and $7.74 \mathrm{~mm}$, while for canine, respective values were $7.75 \mathrm{~mm}$ and $7.71 \mathrm{~mm}$. These findings are comparable to those reported by Melo et al. [23] who implied that the findings are not by the "ideal tooth dimensions." We failed to find any study that evaluated widths and lengths of maxillary anterior teeth at various crown levels, and hence, it was difficult to draw comparisons.

Attempts have been made to curtail possible sources of error and bias in the present study. The main limitation of the study is perhaps its relatively smaller sample size. Future studies with a larger and more diverse sample may reveal interesting results. To limit human error in data collection, all procedures have been carried out by a single operator, where equipment has been used such as cameras and intraoral scanners; the inherent margin of error of the said equipment may have been incorporated, but as such, it does not appear to affect the study results.

In the context of external validity, the results of the present study are generalizable to the Pakistani population in particular and the Southeast Asian population in general. The subjects for this study have been selected from the general population presenting to institute's OPD. Since it is a purely observational study, the effect of any intended 


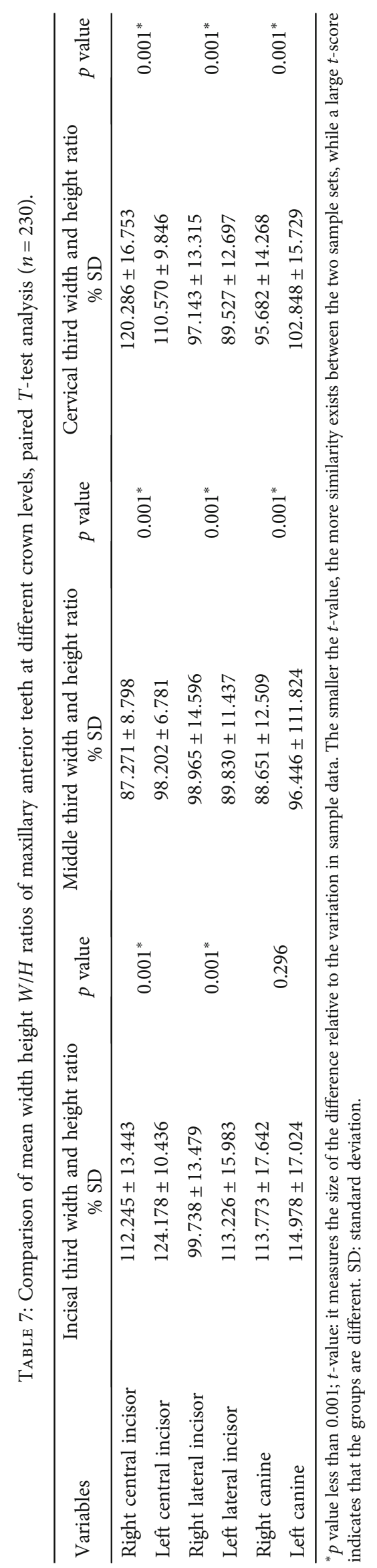


interventions and their subsequent outcomes is ruled out by default. If the study were to be repeated in the same population with a different sample, it should yield similar results. However, if subjects from different ethnic backgrounds are selected, results may vary.

\section{Conclusions}

The results of this revealed the following outcome.

(1) There was a significant difference when the mean mesiodistal widths and incisocervical lengths of maxillary anterior teeth obtained through $2 \mathrm{D}$ photographs were compared with 3D models and standard plaster models, whereas no difference was found between maxillary anterior teeth width of $3 \mathrm{D}$ and plaster models. The $3 \mathrm{D}$ dental model analysis is accurate and reliable

(2) The width and height ratios in the studied population were different at various crown levels. The dimensions of teeth varied from the incisal to the cervical part of the crown. In the current study, the width-height ratio for the right central incisor was $112.24 \%$ at incisal, $87.27 \%$ middle, and $120.286 \%$ at the cervical level of the crown, respectively. The mean $W / H$ ratio was $106.59 \%$. In the left central incisor, these ratios were $124.17 \%, 98.2 \%$, and $110.57 \%$, respectively, with a mean ratio of $110.98 \%$

(3) Likewise, for the right lateral incisor, width-height ratios were $99.7 \%, 98.9 \%$, and $97.1 \%$, while the mean ratio was $98.56 \%$. In the left lateral incisor, mean width-height ratios were $113.22 \%, 89.8 \%$, and $89.52 \%$ whereas, the mean ratio was $97.5 \%$

(4) The width-height ratios in right canine tooth were $113.77 \%, 88.65 \%$, and $95.68 \%$ (mean: $99.36 \%$ ), while for the left canine, the ratios were $114.97 \%, 96.44 \%$, and $102.84 \%$ (mean: $104.75 \%$ )

(5) Hence, rather than relying on a fixed and single ratio of $78 \%$ to $80 \%$, the clinician should adopt different width-height ratios to restore teeth with the optimum esthetic outcome

\section{Data Availability}

The raw data used to support the findings of this study are included within the article.

\section{Conflicts of Interest}

The authors declare no conflict of interest.

\section{Authors' Contributions}

N.A, M.S.H, and Z.A.G planned and designed the present work, and N. A, M.S.H, and J. S were responsible for realizing the work. N. A, A. A, and J. S were responsible for the data acquisition and analysis. N. A, M.S.H, A.A., and
M.K.A drafted and revised the manuscript. NA, MKA, M.S.H, and Z.A.G approved the final version of the manuscript. All authors read and approved the final manuscript. M.S.H and M.K.A contributed equally to this work and are corresponding authors.

\section{Acknowledgments}

The authors thank all participants, the School of Dental Sciences, Health Campus, Universiti Sains Malaysia, and Altamash Institute of Dental Medicine, Pakistan, for the support and facilitation in this study.

\section{References}

[1] A. Al Taki, A. M. Hamdan, Z. Mustafa, M. Hassan, and S. AbuAlhuda, "Smile esthetics: impact of variations in the vertical and horizontal dimensions of the maxillary lateral incisors," Eur J Dent, vol. 11, no. 4, pp. 514-520, 2017.

[2] A. S. Alqahtani, S. R. Habib, M. Ali, A. S. Alshahrani, N. M. Alotaibi, and F. A. Alahaidib, "Maxillary anterior teeth dimension and relative width proportion in a Saudi subpopulation," Journal of Taibah University Medical Sciences, vol. 16, no. 2, pp. 209-216, 2021.

[3] N. Sandeep, P. Satwalekar, S. Srinivas, C. S. Reddy, G. R. Reddy, and B. A. Reddy, "An analysis of maxillary anterior teeth dimensions for the existence of golden proportion: clinical study," Journal of International Oral Health: JIOH, vol. 7, no. 9, pp. 18-21, 2015.

[4] M. Khan, M. A. Khan, and U. Hussain, "Clinical crown length, width and the width/length ratio in the maxillary anterior region in a sample of Mardan population," Pakistan Oral \& Dental Journal, vol. 35, no. 4, pp. 738-741, 2021.

[5] P. H. Yuan, I. A. Evangelina, and G. Gayatri, "Comparison of crown width, length, width/length ratio of maxillary anterior teeth between male and female dental students," Padjadjaran Journal of Dentistry, vol. 30, no. 3, pp. 170-177, 2018.

[6] P. Sitthiphan, N. Viwattanatipa, P. Amornvit, B. Shrestha, M. L. T. Srithavaj, and M. K. Alam, "Comparison of maxillary anterior teeth crown ratio (width/length) between gender in Laotian population," International Medical Journal, vol. 22, no. 3, pp. 199-205, 2015.

[7] N. Ahmed, M. S. B. Halim, Z. A. Ghani et al., "A 2D photographic and 3D digital dental model analysis of golden percentage in maxillary anterior teeth," BioMed Research International, vol. 2021, Article ID 6674400, 7 pages, 2021.

[8] J. D. Sterrett, T. Oliver, F. Robinson, W. Fortson, B. Knaak, and C. M. Russell, "Width/length ratios of normal clinical crowns of the maxillary anterior dentition in man," Journal of Clinical Periodontology, vol. 26, no. 3, pp. 153-157, 1999.

[9] P. Magne, G. O. Gallucci, and U. C. Belser, "Anatomic crown width/length ratios of unworn and worn maxillary teeth in white subjects," The Journal of Prosthetic Dentistry, vol. 89, no. 5, pp. 453-461, 2003.

[10] S. J. Chu, "Range and mean distribution frequency of individual tooth width of the maxillary anterior dentition," Practical Procedures and Aesthetic Dentistry, vol. 19, no. 4, pp. 209215, 2007.

[11] F. Shahid, M. K. Alam, and M. F. Khamis, "Maxillary and mandibular anterior crown width/height ratio and its relation to various arch perimeters, arch length, and arch width 
groups," European Journal of Dentistry, vol. 9, no. 4, pp. 490499, 2015.

[12] X.-J. Yin, B.-Y. Wei, X.-P. Ke et al., "Correlation between clinical parameters of the crown and gingival morphology of anterior teeth and periodontal biotypes," BMC Oral Health, vol. 20, no. 1, pp. 1-8, 2020.

[13] S. Jain, M. Reddy, P. Raghav et al., "Assessment of tooth proportions in an aesthetically acceptable smile," Journal of Clinical and Diagnostic Research, vol. 9, no. 4, pp. ZC01-ZC04, 2015.

[14] A. S. Bidra, F. Uribe, T. D. Taylor, J. R. Agar, P. Rungruanganunt, and W. P. Neace, "The relationship of facial anatomic landmarks with midlines of the face and mouth," Journal of Esthetic Dentistry, vol. 102, no. 2, pp. 94103, 2009.

[15] D. H. Ward, "Proportional smile design using the recurring esthetic dental (RED) proportion," Dental Clinics of North America, vol. 45, no. 1, pp. 143-154, 2001.

[16] J. C. Kois, "Digital smile design meets the dento-facial analyzer: optimizing esthetics while preserving tooth structure," Compendium of Continuing Education in Dentistry (Jamesburg, NJ: 1995), vol. 37, no. 1, pp. 46-50, 2016.

[17] M. L. Pitel, K. M. Raley-Susman, and A. Rubinov, "Preferences of lay persons and dental professionals regarding the recurring esthetic dental proportion," Journal of Esthetic and Restorative Dentistry, vol. 28, no. 2, pp. 102-109, 2016.

[18] S. K. Sah, H. D. Zhang, T. Chang et al., "Maxillary anterior teeth dimensions and proportions in a central mainland Chinese population," The Chinese Journal of Dental Research, vol. 17, no. 2, pp. 117-124, 2014.

[19] A. Orozco-Varo, G. Arroyo-Cruz, R. Martínez-De-Fuentes, and E. Jiménez-Castellanos, "Biometric analysis of the clinical crown and the width/length ratio in the maxillary anterior region," The Journal of Prosthetic Dentistry, vol. 113, no. 6, pp. 565-570.e2, 2015.

[20] A. Aldegheishem, A. Azam, E. Al-Madi, L. Abu-Khalaf, B. Bani Ali, and L. Anweigi, "Golden proportion evaluation in maxillary anterior teeth amongst Saudi population in Riyadh," The Saudi Dental Journal, vol. 31, no. 3, pp. 322-329, 2019.

[21] J. W. Song, R. Leesungbok, S. J. Park, S. H. Chang, S. J. Ahn, and S. W. Lee, "Analysis of crown size and morphology, and gingival shape in the maxillary anterior dentition in Korean young adults," The Journal of Advanced Prosthodontics, vol. 9, no. 4, pp. 315-320, 2017.

[22] A. R. Al-Khatib, Z. A. Rajion, S. M. Masudi, R. Hassan, P. J. Anderson, and G. C. Townsend, "Tooth size and dental arch dimensions: a stereophotogrammetric study in Southeast Asian Malays," Orthodontics \& Craniofacial Research, vol. 14, no. 4, pp. 243-253, 2011.

[23] M. Melo, F. Ata-Ali, J. Huertas et al., "Revisiting the maxillary teeth in 384 subjects reveals a deviation from the classical aesthetic dimensions," Scientific Reports, vol. 9, no. 1, p. 730, 2019. 